\title{
Brain-Derived Neurotrophic Factor Modulates Cerebellar Plasticity and Synaptic Ultrastructure
}

\author{
Alexandre R. Carter, ${ }^{1}$ Chinfei Chen, ${ }^{2}$ Phillip M. Schwartz, ${ }^{1}$ and Rosalind A. Segal ${ }^{1}$ \\ ${ }^{1}$ Department of Pediatric Oncology, Dana Farber Cancer Institute and Department of Neurobiology, Harvard Medical \\ School, Boston, Massachusetts 02115, and 'Division of Neuroscience, Department of Neurology, Children's Hospital, \\ Boston, Massachusetts 02115
}

\begin{abstract}
Neurotrophins are key regulators of neuronal survival and function. Here we show that TrkB, the receptor for brain-derived neurotrophic factor (BDNF), is located at parallel fiber to Purkinje cell (PF/PC) synapses of the cerebellum. To determine the effects of TrkB receptor activation on synapse formation and function, we examined the parallel fiber to Purkinje cell synapses of mice with a targeted deletion of the BDNF gene. Although Purkinje cell dendrites are abnormal in BDNF -/mice, PF/PC synapses are still able to form. Immunohistochemical analysis of mutant animals revealed the formation of numerous PF/PC synapses with the appropriate apposition of presynaptic and postsynaptic proteins. These synapses are functional, and no differences were detected in the waveform of
\end{abstract}

Information processing depends on the ability of neurons to modify the strength of their connections. Considerable evidence now implicates the neurotrophins as an important class of endogenous modulators of synaptic function. Neurotrophin expression and release are upregulated by neuronal activity (Canossa et al., 1997), and neurotrophins potentiate neurotransmission and plasticity (Lu and Chow, 1999; McAllister et al., 1999; Schuman, 1999). Brain-derived neurotrophic factor (BDNF) acting through the receptor tyrosine kinase TrkB has been implicated in the plasticity of central synapses (Lu and Figurov, 1997). Adding BDNF to dissociated rat hippocampal cultures (Lessmann et al., 1994; Levine et al., 1995) potentiates synaptic activity. A longlasting potentiation is seen with the addition of BDNF to rat hippocampal slices (Kang and Schuman, 1995a,b). In addition, BDNF plays a role in short-term plasticity, including paired-pulse facilitation (PPF) (Patterson et al., 1996; Stoop and Poo, 1996; Gottschalk et al., 1998), and the response to repetitive stimulation (Figurov et al., 1996; Gottschalk et al., 1998; Pozzo-Miller et al., 1999). Both long- and short-term plasticity are impaired in the hippocampus of BDNF -/- mice (Korte et al., 1995), and the

Received March 19, 2001; revised Oct. 26, 2001; accepted Nov. 27, 2001.

This work was supported by grants from National Institutes of Health (NIH) (NS37757 to R.A.S.) and the Howard Hughes Medical Institute (Postdoctoral Research Fellowship for Physicians to C.C.). A.R.C. was supported by a fellowship from NIH (5F31LM00040-05), and R.A.S. was supported by a Klingenstein Fellowship. In accordance with the Harvard conflict of interest guidelines, we note that R.A.S. has a financial interest in Curis Inc. We thank Dr. Tom Schwarz and Dr. Wade Regehr for their helpful comments. We thank Maria Ericsson and Louise Trakimas for tissue preparation and training for electron microscopy, Pieter Dikkes for Golgi staining, Anita Bhattacharyya and John Alberta for training for deconvolution microscopy, and Erin Berry for technical assistance.

Correspondence should be addressed to Rosalind A. Segal, Department of Pediatric Oncology, Dana 620, Dana Farber Cancer Institute, 44 Binney Street, Boston, MA 02115. E-mail: rosalind_segal@dfci.harvard.edu.

Copyright (C) 2002 Society for Neuroscience $\quad 0270-6474 / 02 / 221316-12 \$ 15.00 / 0$ evoked EPSCs, the amplitude of spontaneous mini-EPSCs, or the response to prolonged $10 \mathrm{~Hz}$ stimulus trains. However, paired-pulse facilitation, a form of short-term plasticity, is significantly decreased in BDNF -/- mice. Detailed ultrastructural analysis of the presynaptic terminals demonstrated that this change in synaptic function is accompanied by an increase in the total number of synaptic vesicles in mutant mice and a decrease in the proportion of vesicles that are docked. These data suggest that BDNF regulates both the mechanisms that underlie short-term synaptic plasticity and the steady-state relationship between different vesicle pools within the terminal.

Key words: neurotrophin; BDNF; Trk receptor; cerebellum; facilitation; ultrastructure; presynaptic plasticity addition of BDNF reverses these defects (Korte et al., 1996a,b; Patterson et al., 1996; Pozzo-Miller et al., 1999). Because presynaptic mechanisms are thought to underlie paired-pulse facilitation (Katz and Miledi, 1968; Zucker, 1989; Schulz et al., 1994; Atluri and Regehr, 1996) and contribute to the response to repetitive stimulation (Kreitzer and Regehr, 2000), BDNF may modulate presynaptic function ( $\mathrm{Li}$ et al., 1998; Martinez et al., 1998; PozzoMiller et al., 1999).

Synapses with low probability of release can undergo a pronounced modulation of synaptic activity (Bolshakov and Siegelbaum, 1995) and may be more likely to reveal the functional effects of neurotrophins (Berninger et al., 1999). In the cerebellum, granule cell axons, called parallel fibers, form numerous synapses onto Purkinje cell dendrites in the molecular layer. These synapses are excitatory, exhibit short-term plasticity in the form of facilitation, and characteristically exhibit a low probability of release (Atluri and Regehr, 1996; Sabatini and Regehr, 1997). Because granule cells synthesize BDNF (Hofer et al., 1990) and because the receptor TrkB is expressed by both granule cells (Klein et al., 1990; Segal et al., 1995) and Purkinje cells (Klein et al., 1990), the parallel fiber to Purkinje cell (PF/PC) synapse is well suited for studying the role of BDNF on shortterm synaptic plasticity.

We examined the effect of BDNF deficiency at the $\mathrm{PF} / \mathrm{PC}$ synapse in the mouse cerebellum using animals with a targeted deletion of BDNF (Ernfors et al., 1994). Numerous functional $\mathrm{PF} / \mathrm{PC}$ synapses form in these animals. The finding that TrkB is located at $\mathrm{PF} / \mathrm{PC}$ synapses supports the idea that BDNF can directly modulate short-term synaptic plasticity. Electrophysiologic analysis of the $\mathrm{PF} / \mathrm{PC}$ synapse of BDNF -/- mice revealed preserved neurotransmission but a significant decrease in PPF. This specific impairment of PPF is associated with an 
accumulation of synaptic vesicles and a lengthening of the active zone. These observations implicate BDNF as an important endogenous synaptic factor that regulates short-term synaptic plasticity as well as synaptic ultrastructure. Identification of the structural changes that accompany changes in plasticity contributes to our understanding of the molecular mechanisms underlying activity-dependent synaptic plasticity.

\section{MATERIALS AND METHODS}

BDNF mutant mice. Breeding pairs of BDNF +/- mice (Ernfors et al., 1994) were purchased from Jackson Laboratories (Bar Harbor, ME). Genotypes of animals were determined via PCR using three oligonucleotide primers: oIMR132: 5'-GGG AAC TTC CTG ACT AGG GG-3'; oIMR133: 5' -ATG AAA GAA GTA AAC GTC CAC-3'; and oIMR134: 5'-CCA GCA GAA AGA GTA GAG GAG-3'.

The PCR was run under standard conditions. Primers 132 and 133 amplify a $\sim 340$ bp product from the targeted BDNF allele. Primers 133 and 134 amplify a $\sim 275$ bp band from the wild-type (WT) BDNF allele. PCR of heterozygous animals yielded both amplification products. BDNF - / - pups weighed one-third to two-thirds as much as littermates, depending on age, and were severely ataxic. BDNF $-/-$ pups generally survive until the third postnatal week.

Immunohistochemistry. Midsagittal cerebellar sections $(8 \mu \mathrm{m})$ were obtained from postnatal day (P) 8, P15, and P24 wild-type and BDNF $-/-$ mice as described (Schwartz et al., 1997). Anesthetized mice were perfused with $4 \%$ paraformaldehyde in $0.2 \mathrm{M}$ phosphate buffer, and cryoprotected brains were cut on a Leica CM 3050 cryostat. For immunohistochemistry, cerebellar sections were incubated in a PBS blocking solution containing 5\% normal goat serum and $0.1 \%$ Triton X-100. Incubations in primary antibody were performed in the same blocking solution. The antibodies used were as follows: anti-calbindin-D, 1:500 (CL-300, Sigma, St. Louis, MO); mouse anti-SV2, 1:200 (kind gift of K. M. Buckley, Harvard Medical School); anti-TrkB, 1:2000 (Chemicon, Temecula, CA); anti-synapsin, 1:100 (Chemicon); and anti-GluR $\delta 1 / 2$, 1:25 (Chemicon). Incubations with primary antibodies were performed overnight at $4^{\circ} \mathrm{C}$. Immunostaining was visualized using cy3-conjugated goat anti-mouse IgG, 1:200 (Jackson Immunochemicals, West Grove, PA); Alexa Fluor 488 goat anti-mouse IgG green, 1:500 (Molecular Probes, Eugene, OR); or Alexa Fluor 568 goat anti-rabbit IgG red, 1:500 (Molecular Probes) for 90-120 min at room temperature. Sections were washed and then mounted in GelTol aqueous mounting medium (Immunotech, Marseille, France). DeltaVision restoration fluorescence microscopy was performed on an Olympus fluorescence microscope configured with a DeltaVision stage and software (Applied Precision Inc., Issaquah, WA). Immunofluorescent sections were viewed with a $100 \times$ objective (numerical aperture 1.4). Z-series $(200.2 \mu \mathrm{m}$ serial optical sections) were acquired, and softWoRx imaging software (Applied Precision) was used to perform a blind deconvolution on a Silicon Graphics workstation. Final images were representative z-series rendered in softWoRx Volume Viewer unless indicated otherwise. Statistical significance for the correlation between staining patterns was established by calculating for each wavelength the number of pixels with an intensity $1 \mathrm{SD}$ above the mean within a known area. In double-labeled samples, synaptic structures were selected in only one wavelength without knowledge of the second wavelength, which was then restored after the selection of structures. Staining in both wavelengths was considered associated only if no measurable distance existed between the two structures within the single optical section where they were defined or within an adjacent optical section. The probability of two pixels for each wavelength being randomly located in the same position or in one of the eight adjacent positions is given by: (pixels positive for wavelength $1 /$ total pixels) $\times$ (pixels positive for wavelength $2 /$ total pixels $) \times 9$. Statistical significance was determined by a two-tailed unpaired $t$ test assuming unequal variances.

Stensaas-modified Golgi stain. Age P15 BDNF +/+ and BDNF - /mice were perfused transcardially with $4 \%$ paraformaldehyde in $0.1 \mathrm{M}$ sodium phosphate. Brains were immediately removed and immersed 48 $\mathrm{hr}$ in Stensaas solution containing $85 \mathrm{~mm}$ potassium dichromate, $151 \mathrm{~mm}$ chloral hydrate, $3.7 \%$ formaldehyde, and $0.5 \%$ glutaraldehyde. Tissue was rinsed in $0.5 \%$ silver nitrate and transferred to $1.25 \%$ silver nitrate for $4 \mathrm{~d}$. After progressive dehydrations in ethanol, tissue was transferred to low viscosity nitrocellulose, and choloroform was added to harden the nitrocellulose. Sections $(100 \mu \mathrm{m})$ were cut on a sledge microtome and collected in $80 \%$ ethanol, rinsed in $95 \%$ ethanol, and transferred to terpineol. Sections were rinsed in xylene, covered in mounting media, and coverslipped. Images were taken with a Nikon Eclipse E800 microscope at $100 \times$ magnification. Multiple images in different focal planes were taken of individual Purkinje cells. The focused portions of each image were combined to bring the entire dendritic arbor into focus.

Electrophysiology. Synaptic currents were recorded from freshly cut transverse slices of cerebellar vermis of P14-P17 BDNF $-/-$ mice and their wild-type littermates as described previously (Atluri and Regehr, 1996; Chen and Regehr, 1997). Briefly, slices were maintained in an oxygenated $\left(95 \% \mathrm{O}_{2} / 5 \% \mathrm{CO}_{2}\right)$ external solution containing (in $\mathrm{mM}$ ): 125 $\mathrm{NaCl}, 2.5 \mathrm{KCl}, 2.6 \mathrm{NaHCO}_{3}, 1.25 \mathrm{NaH}_{2} \mathrm{PO}_{4}, 25$ glucose, $2 \mathrm{CaCl}_{2}$, and 1 $\mathrm{MgCl}_{2}$. The external recording solution also contained $20 \mu \mathrm{M}$ bicuculline to block IPSCs (Sigma). Whole-cell patch-clamp recordings of Purkinje cells were obtained using 1.0-1.5 $\mathrm{M} \Omega$ electrodes containing (in $\mathrm{mm}$ ): 35 CsF, $100 \mathrm{CsCl}, 10$ EGTA, 10 HEPES, and 0.1 D600, pH 7.4. Holding potential was maintained at $-40 \mathrm{mV}$ to inactivate voltage-dependent calcium conductances. Access resistance $(<5 \mathrm{M} \Omega$ after series resistance compensation), leak current $(<100 \mathrm{pA})$, and the time course of decay of the EPSC $(<6 \mathrm{msec})$ were monitored continuously, and cells that did not meet these criteria were rejected from analysis. Parallel fibers were stimulated with a glass electrode filled with extracellular solution and positioned several hundred micrometers from the recording electrode.

Paired-pulse facilitation protocol involved measurement of the peak amplitude of EPSCs elicited by pairs of stimuli, separated by a randomized interstimulus interval (ISI) ranging from 10 to $500 \mathrm{msec}$. Pairs of EPSCs were interleaved with EPSCs elicited by a single stimulus. The average of three to five trials was used to calculate the percentage facilitation $[100 \times(\mathrm{A} 2-\mathrm{Al}) / \mathrm{A} 1]$. A1 and $\mathrm{A} 2$ are the average peak amplitude of the first and second EPSC, respectively, in response to a single stimulation. At intervals shorter than $100 \mathrm{msec}, \mathrm{A} 2$ is measured from the waveform obtained by subtracting the average single EPSC response from the average EPSC response to a pair of stimuli.

Mini-EPSCs (mEPSCs) were recorded as described previously (Chen and Regehr, 1997). Extracellular solution contained $0.25 \mu \mathrm{M}$ TTX and 20 $\mu \mathrm{M}$ bicuculline. Data were recorded in $20 \mathrm{sec}$ epochs, sampled at $2.5 \mathrm{kHz}$, and filtered digitally at $500 \mathrm{~Hz}$. Inclusion criteria were an $8 \mathrm{pA}$ threshold, a minimum rate of rise of $0.4 \mathrm{pA} / \mathrm{msec}$, and a decay time constant between 3 and $20 \mathrm{msec}$. Experiments used to calculate the average cumulative histogram distributions of mEPSC amplitude contained $>4000$ mEPSC events. Changes in mEPSC frequencies have been used as an indicator of a presynaptic process when the same population of synapses is studied before and after a pharmacological manipulation. However, the frequency of mEPSCs cannot be used as a presynaptic indicator when comparing population of synapses from different slices. The angle of the slice and the number of intact presynaptic fibers vary significantly from slice to slice and would thus make mEPSC frequency comparison between BDNF-/- and WT mice difficult to interpret.

Because trains of stimuli can result in recurrent excitation and activation of endogenous G-protein-mediated modulation of synaptic currents, experiments using repetitive stimulation were recorded in an external solution containing the $\mathrm{GABA}_{\mathrm{B}}$ receptor antagonist CGP55845a $(2 \mu \mathrm{M})$, the adenosine $\mathrm{A} 1$ receptor antagonist 8-cyclopentyl-1,3-dipropylxanthine $(5 \mu \mathrm{M})$, and the mGlu-RIII antagonist $(R S)$ - $\alpha$-cyclopropyl-4-phosphonophenylglycine $(30 \mu \mathrm{M})$. Frequencies $>10 \mathrm{~Hz}$ resulted in desynchronization of EPSCs during a train of stimuli, attributable to accumulation of presynaptic residual calcium (Atluri and Regehr, 1998; Kreitzer and Regehr, 2000). Therefore we did not analyze the synaptic response to higher frequency stimulation. All recordings were digitized with a 16 bit digital-to-analog converter (Instructec, Great Neck, NY), with pulse control software, and analyzed using Igor Pro software (Wavemetrics, Lake Oswego, OR) and custom macros. All experiments were performed at $25^{\circ} \mathrm{C}$.

Electron microscopy. Brains were obtained from P14 wild-type and BDNF $-/-$ mice anesthetized and perfused with $4 \%$ paraformaldehyde and $2 \%$ glutaraldehyde in $0.2 \mathrm{M}$ phosphate buffer. Blocks from midsagittal cerebellar vermis in folia $\mathrm{V}$ were stained with $1 \%$ osmium tetroxide/ $1.5 \%$ potassium ferrocyanide, bathed in $1 \%$ uranyl acetate, and ethanol dehydrated and placed in propylene oxide for $1 \mathrm{hr}$. Infiltration with Epon/Araldite mixed 1:1 with propylene oxide was performed overnight. Samples were embedded in Epon/Araldite. Thin sections from sample were photographed under a JEOL 1200EX electron microscope. Negatives were scanned into Adobe Photoshop. Images of individual synapses were analyzed using NIH Image 3.1 (National Institutes of Health, Bethesda, MD). Scale bars were taken from scans of original electron 
micrograph negatives. All synapses were analyzed without knowledge of genotype. For each synapse the number of synaptic vesicles and the length of the postsynaptic density (PSD) were quantitated. Vesicle distribution was quantitated by measuring the distance from the center of each synaptic vesicle to the closest point at the active zone. Docked vesicles were defined as those located within $50 \mathrm{~nm}$ (one vesicle diameter) of the active zone.

\section{RESULTS}

\section{The TrkB receptor is located at PF/PC synapses in wild-type mice}

The BDNF receptor TrkB is expressed by both granule cells and Purkinje cells. To determine whether TrkB is appropriately located to mediate synapse-specific effects of BDNF, the expression pattern of TrkB protein in the cerebellum was analyzed. In both wild-type (Fig. $1 A$ ) and mutant mice (data not shown), significant TrkB immunostaining was seen throughout the molecular layer and in Purkinje cell bodies and main dendrites. To clarify the subcellular localization of TrkB, cerebellar sections of wild-type mice were double labeled with the TrkB antibody and an antibody against calbindin, which is expressed specifically in Purkinje cells. Staining was visualized by high-resolution wide-field restoration microscopy. Nanomotor-guided focusing allows for image acquisition at precise distance intervals throughout the volume of the sample. On the basis of the information in the stack of optical sections, a deconvolution algorithm identifies out-of-focus light and returns it to its source using a point-spread function. Although the original optical sections reveal the general dendritic morphology of a Purkinje cell (Fig. 1B), the increased contrast, decreased background, and sharper borders of the deconvolved optical sections (Fig. 1C) allow for the identification of details on the order of $175 \mathrm{~nm}$.

Double labeling for calbindin and TrkB in wild-type cerebellum (Fig. 1D-F) revealed the presence of numerous TrkBpositive puncta (red) adjacent to and partially overlapping with the tips of calbindin-positive dendritic spines (green). There is a high degree of association between calbindin-positive spines and TrkB puncta. We found that $75 \%( \pm 6 \%$ SEM) of calbindinpositive spines $(n=116)$ were associated with TrkB puncta and that $79 \%( \pm 1 \%$ SEM $)$ of TrkB puncta $(n=121)$ were associated with calbindin-positive spines. This degree of association is significantly higher than that predicted by chance alone $(20 \pm 0.5 \%$ SEM; $p<0.01 ; t$ test).

The localization of TrkB immunostaining at spine tips is consistent with a synaptic localization of TrkB at PF/PC synapses. Double labeling was performed using an antibody against the glutamate receptor delta 2 subunit (GluR $\delta 2$ ) and an antibody against calbindin. GluR $\delta 2$ is a useful marker for PF/PC synapses because after an initial period of expression throughout Purkinje cells, this receptor subunit becomes targeted specifically to the spines receiving parallel fiber afferents (Landsend et al., 1997). Double labeling with an antibody against calbindin (green) and an antibody against GluR $\delta 2$ (red) (Fig. $1 G-I$ ) yielded numerous GluR $\delta 2$ puncta that overlapped significantly with calbindinpositive dendrites and spines. We found that $74 \%( \pm 5 \% \mathrm{SEM})$ of calbindin-positive spines $(n=91)$ are associated with GluR $\delta 2$, whereas $65 \%( \pm 4 \% \mathrm{SEM})$ of GluR $\delta 2$ puncta $(n=100)$ are associated with calbindin-positive spines. This degree of association is significantly higher than that predicted by chance alone (14 $\pm 1 \%$ SEM; $p<0.01 ; t$ test). The finding that the degree of association between calbindin-positive spines and TrkB puncta, and between spines and GluR $\delta 2$, is comparable and that TrkB and GluR $\delta 2$ have similar staining patterns relative to calbindin strongly suggests that TrkB, like GluR $\delta 2$, is localized to PF/PC synapses. In fact, TrkB staining often appeared to be even more specifically associated with the very tips of dendritic spines than did GluR $\delta 2$ (stronger yellow signal in Fig. $1 I$ than in Fig. $1 F$ ). The absence of antibodies of the appropriate species and sensitivity currently make it difficult to determine conclusively the relative positions of TrkB and GluR $\delta 2$.

To further confirm the synaptic localization of TrkB, double labeling with an antibody against the presynaptic protein SV2, a component of synaptic vesicle membranes, and the antibody against TrkB was performed (Fig. $1 J-L$ ). We found that $75 \%$ $( \pm 6.5 \%$ SEM $)$ of SV2 puncta $(n=158)$ are associated with TrkB-positive spines. This degree of association is significantly higher than that predicted by chance alone $(15 \pm 1.1 \%$ SEM; $p<$ $0.01 ; t$ test). Nonetheless, the synaptic localization of the BDNF receptor is appropriate for $\mathrm{BDNF}$ to directly regulate $\mathrm{PF} / \mathrm{PC}$ synapse development and function. As shown here, there is some overlap of TrkB and SV2 puncta, and there is also some overlap of TrkB and calbindin staining. Because of the narrow width of the synaptic cleft $(\sim 30 \mathrm{~nm})$ and the fact that the TrkB antibody recognizes the extracellular domain of the receptor, we cannot determine conclusively on which side of the synaptic cleft TrkB resides.

\section{BDNF is not required for PF/PC synaptogenesis}

The synaptic localization of the BDNF receptor suggests that BDNF may play a crucial role in synapse formation and development. Therefore, the absence of BDNF could preclude PF/PC synapse formation. Previously, the addition of BDNF or the removal of endogenous BDNF with TrkB IgG has been shown to alter Purkinje cell dendritic spine number and morphology (Morrison and Mason, 1998; Shimada et al., 1998). Furthermore, analysis of cerebella in BDNF $-/-$ mice revealed that the dendrites of Purkinje cells are severely atrophied and disorganized in P8 animals (Schwartz et al., 1997). To determine whether the absence of BDNF precludes the formation of synapses onto Purkinje cell dendrites, we first examined Purkinje cell morphology in P8, P15, and P24 wild-type and BDNF mutant mice using an antibody against the Purkinje cell-specific marker calbindin (Fig. 2). Compared with Purkinje cell dendrites of BDNF $+/+$ animals, dendrites of BDNF $-/-$ animals remain less extensive at all ages. Accordingly, this defect is associated with a persistently thinner molecular layer. Nonetheless, there is continued development of Purkinje cell dendrites even in the absence of BDNF because primary, secondary, and tertiary branches are visible in P15 and P24 BDNF -/- mice.

Because the overlap between adjacent dendrites makes it difficult to appreciate the morphology of individual dendritic arbors, cerebella from $\mathrm{P} 15 \mathrm{BDNF}+/+$ and $\mathrm{BDNF}-/-$ mice were stained using a rapid Golgi method (Fig. 3) to visualize individual Purkinje cell arbors. As illustrated, the extent of dendritic arbors in individual BDNF - - - Purkinje cells is reduced when compared with wild-type Purkinje cells (Fig. 3). In BDNF - / - cells, the primary dendrite is shorter and divides into fewer secondary and tertiary branches. Despite their abnormal morphology, BDNF $-/-$ dendrites are studded with numerous spines (Fig. $3 B$, inset, $C$, inset) as in wild-type dendrites (Fig. $3 A$, inset). Because these dendritic spines are the postsynaptic targets of granule cell axons, Purkinje cell dendrites may develop sufficiently to receive synapses from parallel fibers despite the significant effects of BDNF deficit on dendritic morphology.

To determine whether synapses form on Purkinje cell dendritic 

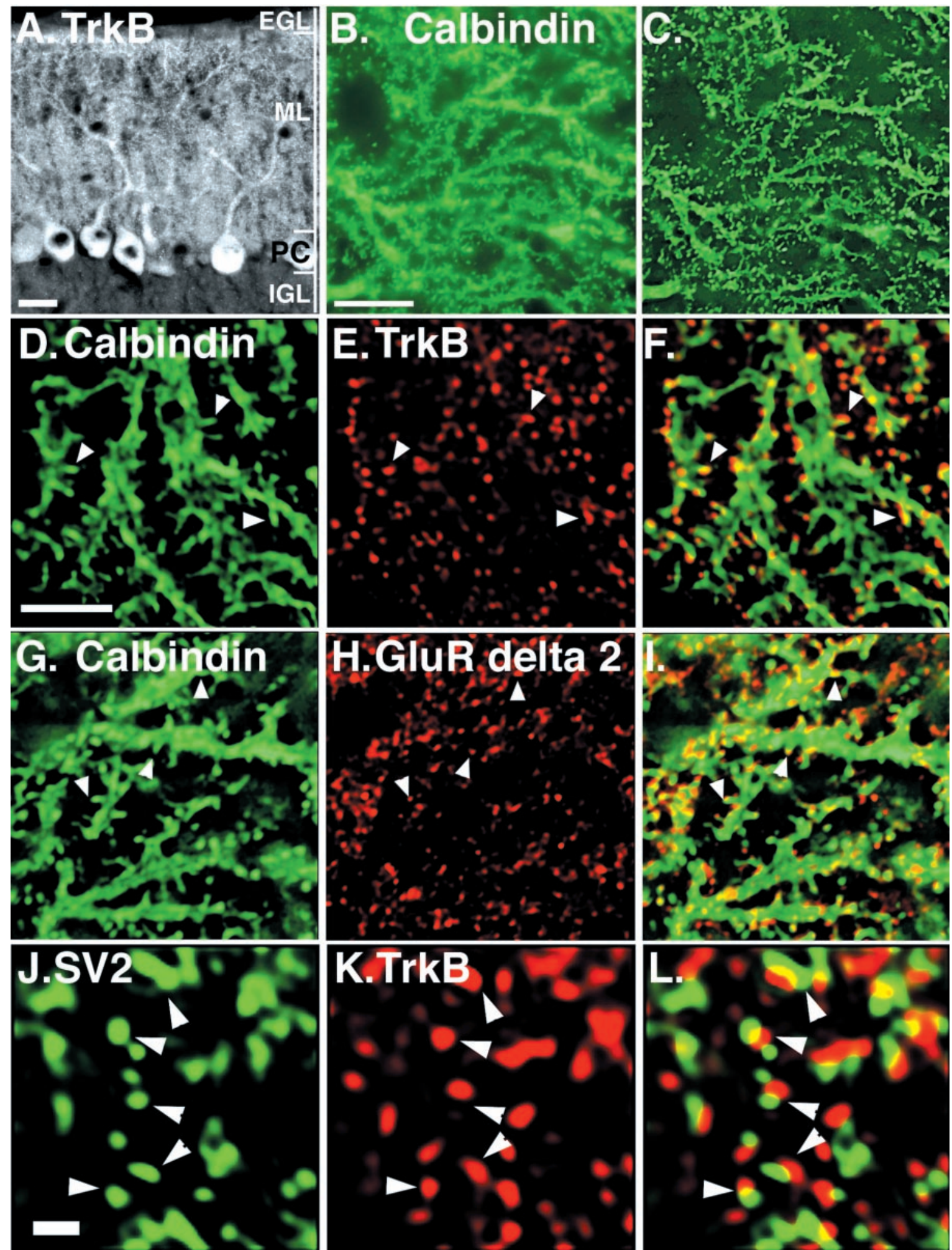

Figure 1. The BDNF receptor, TrkB, is located at $\mathrm{PF} / \mathrm{PC}$ synapses. $A, \mathrm{P} 15$ cerebellum immunolabeled with anti-TrkB. TrkB staining is seen throughout the molecular layer $(M L)$ and in Purkinje cell bodies $(P C)$ and dendrites in BDNF $+/+$ mice. EGL, External granule cell layer; $I G L$, internal granule cell layer. $B, C$, Single optical section through the molecular layer of P15 wild-type cerebellum labeled with anti-calbindin before deconvolution $(B)$ and after deconvolution $(C) . D-F$, Cerebellar molecular layer of P15 wild-type mouse double labeled with anti-calbindin $(D$, green $)$ and anti-TrkB $(E$, red $)$ antibodies. The merged image $(F)$ shows numerous TrkB puncta juxtaposed to and sometimes overlapping with calbindin-positive Purkinje cell dendritic spines (arrowheads). $G-I$, Cerebellar molecular layer of P15 wild-type mouse double labeled with anti-calbindin $(G$, green) and anti-GluR $\delta 2(G l u R$ delta 2) $(H, r e d)$. Merged image $(I)$ shows GluR $\delta 2$-positive overlapping Purkinje cell dendrites and capping Purkinje cell dendritic spines (arrowheads). $J-L$, Cerebellar molecular layer of P15 wild-type mouse double labeled with anti-SV2 (J, green) and anti-TrkB $(K$, red $)$. Merged image $(L)$ shows SV2-positive puncta juxtaposed to and partially overlapping with TrkB-positive puncta (arrowheads). $D-L$ were reconstructed from $5-10$ adjacent optical sections. Scale bars: $A, 20 \mu \mathrm{m} ; B, C, 10 \mu \mathrm{m} ; D-I, 5 \mu \mathrm{m}$.; $J-L, 5 \mu \mathrm{m}$. 

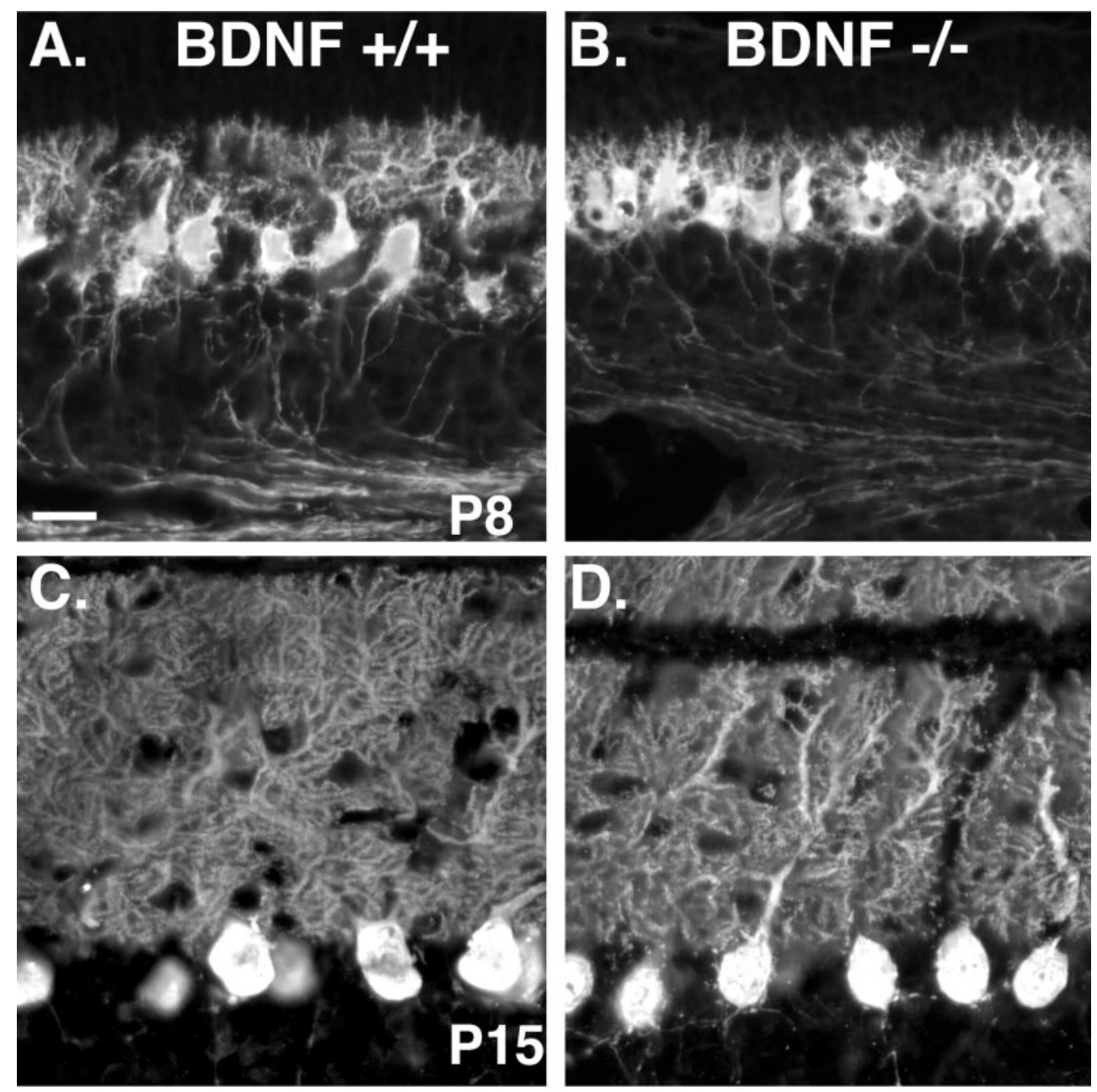

Figure 2. The development of Purkinje cell dendritic arbors in wild-type $(A, C$, $D)$ and BDNF $-/-$ mice $(B, D, F)$. Parasagittal cerebellar sections from $\mathrm{P} 8(A$, $B), \mathrm{P} 15(C, D)$, and $\mathrm{P} 24(E, F)$ mice were immunolabeled with anti-calbindin antibody. In the absence of BDNF, Purkinje cell dendrites are stunted at P8 and undergo significant development over the following 2 weeks, but remain less extensive than in WT mice. Scale bar, $20 \mu \mathrm{m}$.
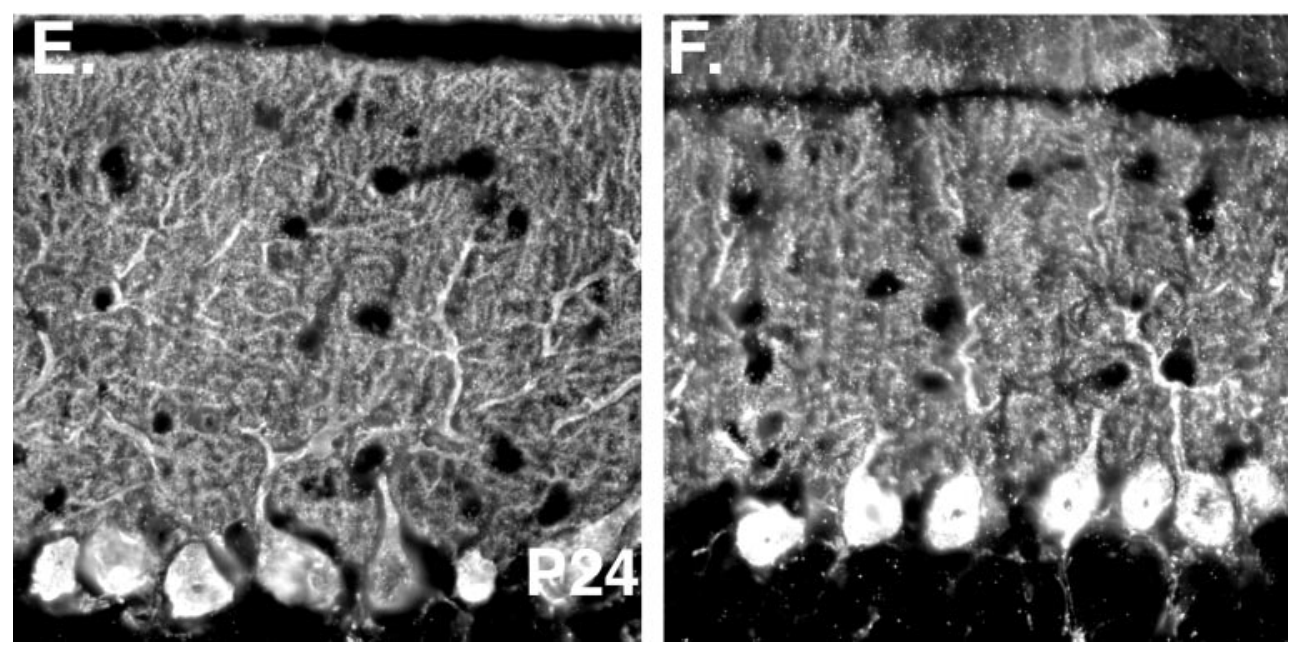

spines from BDNF - /- mice, immunohistochemistry was performed using an antibody against calbindin and a second antibody against glutamate receptor subunit GluR $\delta 2$. Double labeling shows puncta of GluR $\delta 2$ staining that cap calbindin-positive spines (Fig. 4A), suggesting that many of these spines in fact do receive synapses as in the wild-type mouse (Fig. 1I). Quantification of the staining patterns confirmed that $70 \%$ of spines were capped with GluR $\delta 2$ puncta $(n=94)$ and $72 \%$ of GluR $\delta 2$ puncta were found at the tips of calbindin-positive spines $(n=90)$. These values are very close to those determined for $\mathrm{BDNF}+/+$ cere- bella. To visualize presynaptic boutons, antibodies against the presynaptic terminal proteins SV2 and synapsin were used (Fig. $4 B$ ). In the molecular layer of the BDNF $-/-$ cerebellum, numerous puncta immunopositive for both SV2 and synapsin were seen, resulting in a strong yellow signal. These correspond to individual presynaptic terminals. Quantitation revealed that $90 \%$ of SV2 puncta were synapsin positive $(n=106)$ and that $92 \%$ of synapsin puncta were SV2 positive $(n=125)$. This degree of association is significantly higher than that predicted by chance alone $(1 \pm 0.1 \%$ SEM; $p<0.01 ; t$ test $)$. Double-positive puncta 

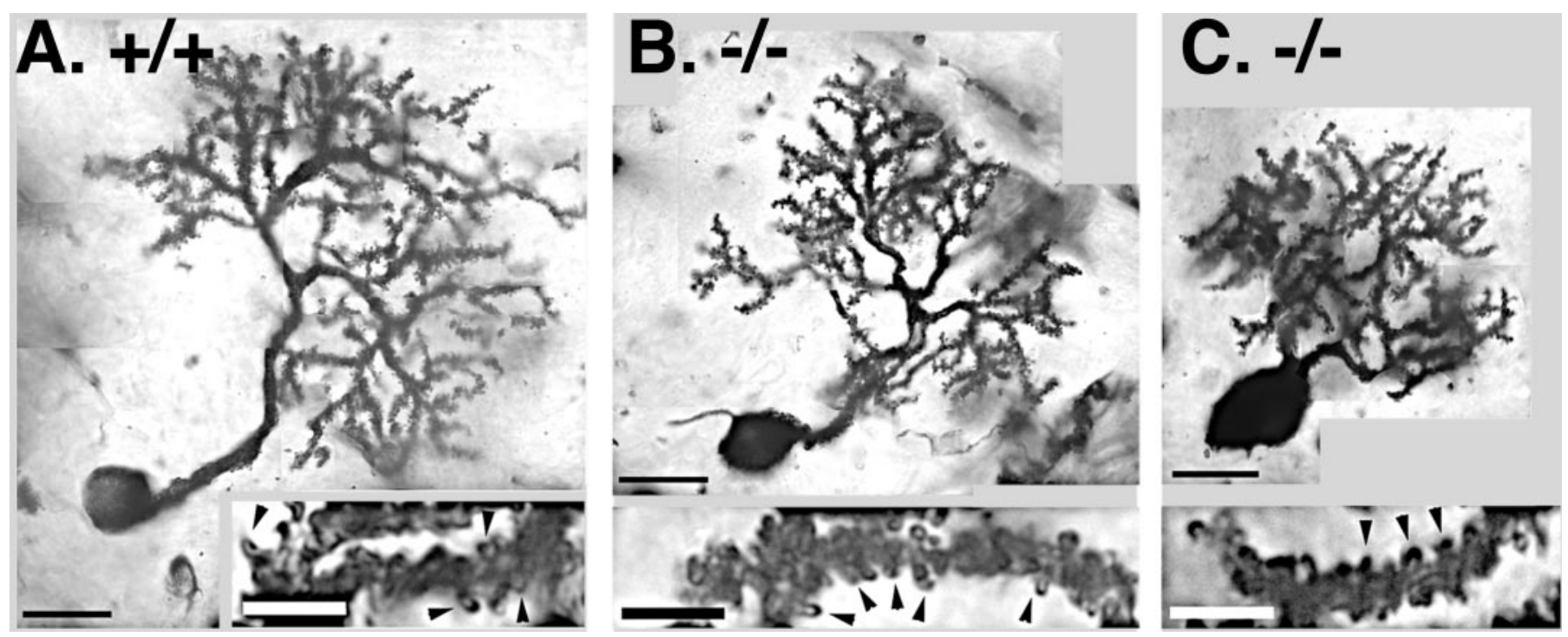

Figure 3. Individual Purkinje cell dendrite morphology in the absence of BDNF. A, Modified Golgi stain resolves the morphology of an individual Purkinje cell dendritic arbor in a P15 wild-type mouse. Inset shows a higher magnification view of a dendritic segment studded with numerous spines (arrowheads). B, C, Two individual Purkinje cells from a P15 BDNF -/- mouse exhibit a significant decrease in the extent of the dendritic arbor. Insets show that dendrites nonetheless carry numerous spines (arrowheads). Scale bars: $A-C, 20 \mu \mathrm{m} ;$ insets, $5 \mu \mathrm{m}$.

were defined as those that overlapped by at least $50 \%$ in the same optical section. To confirm that these accumulations of presynaptic protein correspond to bona fide synapses, we used the antibody against the postsynaptic marker, GluR $\delta 2$. Double labeling revealed that numerous GluR $\delta 2$ puncta were present and juxtaposed to SV2 puncta in the molecular layer of BDNF - /- mice (Fig. $4 C$ ). As predicted, SV2 staining and GluR 82 staining overlap noticeably less than staining for the two presynaptic markers SV2 and synapsin, resulting in much less yellow signal. The staining patterns for SV2, synapsin, calbindin, and GluR $\delta 2$ seen in BDNF $-/-$ mice were very similar to staining patterns observed in BDNF $+/+$ cerebella (data not shown). This demonstrates that even in the absence of BDNF there is development and juxtaposition of the presynaptic and postsynaptic components of the $\mathrm{PF} / \mathrm{PC}$ synapse.

BDNF may regulate synapse number in several systems. Therefore, a quantitative analysis of synapse density in the molecular layer of $\mathrm{BDNF}+/+$ and $-/-$ mice was performed. In cerebellar sections double labeled with an antibody against SV2 and an antibody against GluR $\delta 2$, synapses were defined by the juxtaposition or overlap of puncta of SV2 and GluR $\delta 2$ staining. Synaptic density per $300 \mu^{3}$ was determined from four deconvolved optical $\mathrm{z}$-series in each of three cerebellar subregions (caudal, dorsal, and rostral) in wild-type $(n=3)$ and mutant mice $(n=3)$. A small difference was seen in the overall density of $\mathrm{PF} / \mathrm{PC}$ synapses between wild-type mice (48.4 synapses/300 $\mu^{3} \pm 4.1$ SEM) and mutant mice ( 40.7 synapses $/ 300 \mu^{3} \pm 1.9 \mathrm{SEM} ; p=0.07$ ). Thus, in spite of the marked effect of BDNF on Purkinje cell dendritic morphology and molecular layer thickness, $\mathrm{PF} / \mathrm{PC}$ synapses can form, although their numbers are slightly reduced.

\section{BDNF deficit leads to impaired short-term plasticity}

BDNF enhances neurotransmission and potentiates activitydependent plasticity at hippocampal synapses (Kang and Schuman, 1995a,b; Korte et al., 1995; Patterson et al., 1996). We analyzed neurotransmission across $\mathrm{PF} / \mathrm{PC}$ synapses in thin cerebellar slices from BDNF -/- and wild-type mice aged P14-P17.
We recorded the spontaneous mEPSC as well as the AMPA receptor-evoked EPSCs from Purkinje cells (Chen and Regehr, 1997). Analysis of mEPSC amplitudes showed no difference between BDNF $+/+$ and BDNF $-/-$ synapses (Fig. 5). In addition, evoked EPSCs are similar at BDNF $+/+$ and $-/-$ synapses (Fig. $6 A$ ). These observations suggest that synaptic function is preserved despite the BDNF deficit.

Short-term synaptic plasticity at the $\mathrm{PF} / \mathrm{PC}$ synapse in BDNF-/- mice was examined using pairs of stimuli, separated by varying interstimulus intervals. At the $\mathrm{PF} / \mathrm{PC}$ synapse, pairs of closely spaced stimuli result in the facilitation of synaptic strength (Atluri and Regehr, 1996). This paired-pulse facilitation can be quantified as the change in the peak amplitude of the second EPSC relative to the first (percentage facilitation; see Materials and Methods). For brief interstimulus intervals, the degree of facilitation in $\mathrm{BDNF}-/-$ mice is approximately half that of control levels $(p<0.01$; ANOVA) (Fig. $6 B)$. At longer interstimulus intervals $(>400 \mathrm{msec})$, there is no facilitation in either wild-type or mutant animals. This result suggests that there is an alteration of short-term plasticity at the PF/PC synapse in BDNF $-/-$ mice.

Response to repetitive stimulation is another index of presynaptic function. Parallel fibers were stimulated with a $10 \mathrm{~Hz}$ train for 10 or 50 trials. The ratios of the peak amplitude of the 10th/1st EPSC and the 50th/1st EPSC were determined (Fig. $6 C$ ). The similarity in the 50th/1st impulse between wild-type $(0.70 \pm 0.21$ SEM; $n=6)$ and BDNF $-/-$ mice $(0.53 \pm 0.03 \mathrm{SEM} ; n=5)$ indicates that the synaptic apparatus in the mutant mouse is capable of maintaining neurotransmission over long periods of repetitive stimulation. In contrast, after a short train of stimulation, the 10 th $/ 1$ st ratio is $1.40( \pm 0.08 \mathrm{SEM} ; n=7)$ in wild-type mice and $1.11( \pm 0.06 \mathrm{SEM} ; n=6)$ in BDNF $-/-$ mice. This difference is statistically significant $(p<0.05 ; t$ test). Because PPF is decreased in BDNF $-/-$ mice at an ISI of $100 \mathrm{msec}$, which corresponds to a frequency of $10 \mathrm{~Hz}$, altered short-term plasticity must contribute to this difference seen in the 10 th/1st ratio. Thus 

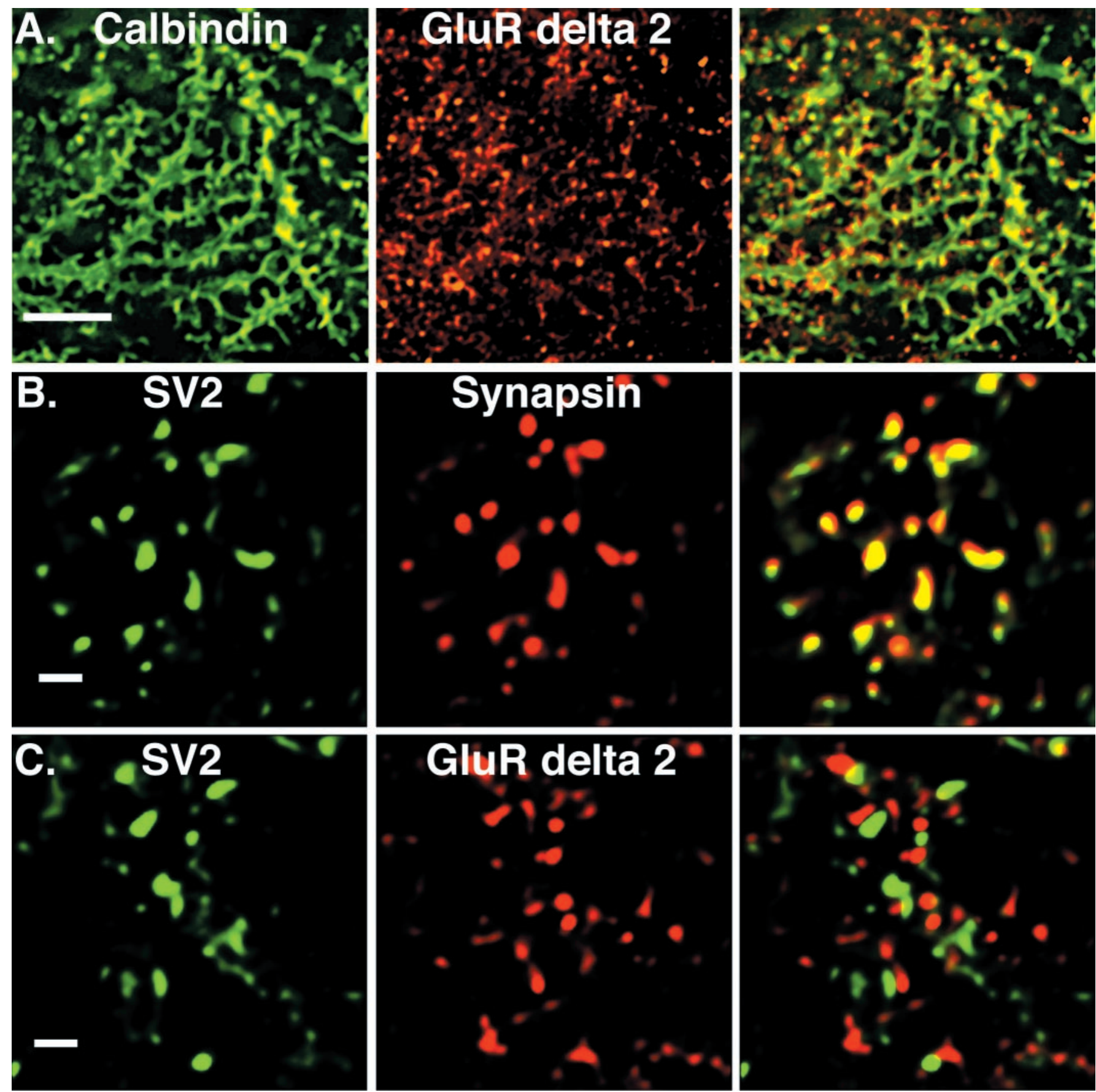

Figure 4. Synaptogenesis in the molecular layer of BDNF -/- cerebellum. A, P15 cerebellum immunolabeled with antibodies against calbindin ( green) and the glutamate receptor subunit GluR $\delta 2$ (GluR delta 2) (red). Numerous calbindin-positive spines are capped by puncta of GluR $\delta 2$ staining characteristic of functional synapses. $B$, Individual presynaptic terminals in the molecular layer immunolabeled with antibodies against the presynaptic terminal proteins SV2 ( green) and synapsin (red) resulting in identical staining patterns. $C$, Immunolabeling with antibodies against SV2 (green) and GluR $\delta 2$ (red) results in staining patterns where the puncta are juxtaposed with much less overlap, consistent with the association of presynaptic terminals with their postsynaptic targets. Images were reconstructed from 5-10 adjacent optical sections. Scale bars: $A, 5 \mu \mathrm{m} ; B, C, 1 \mu \mathrm{m}$.

the evidence for impaired paired-pulse facilitation in the context of normal mEPSCs, normal evoked EPSC, and equivalent response to sustained trains of stimulation argues for a selective deficit in short-term plasticity in $\mathrm{BDNF}-/-$ mice.

To determine whether the effects of BDNF deficit on presynaptic function are reversible, exogenous BDNF was applied to cerebellar slices from $\mathrm{BDNF}-/-$ mice. Under the experimental conditions used (see Materials and Methods), only presynaptic effects of BDNF addition would be detected. The functional deficit in short-term synaptic plasticity evident in the decreased PPF was not reversed by bath application of BDNF after either 30 min or $3 \mathrm{hr}$ of BDNF exposure (data not shown). To be certain that BDNF is capable of stimulating responsive cells in the slice under these conditions, Trk phosphorylation was analyzed. Treat- 
A.

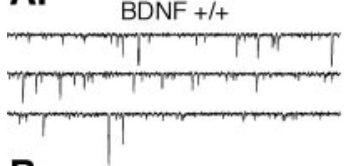

B.
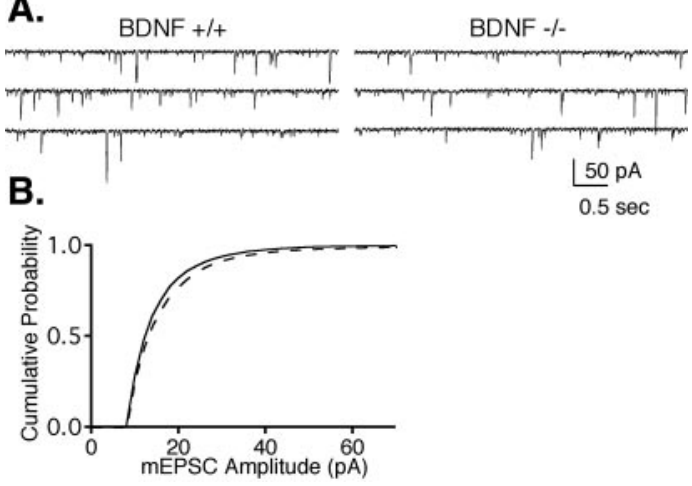

Figure 5. A, Representative consecutive mEPSC traces are shown from a wild-type (left) and a BDNF - $/-($ right $)$ mouse. $B$, The normalized cumulative amplitude distribution for BDNF $+/+(n=4$; solid trace $)$ and BDNF $-/-(n=4$; dashed trace $)$ are similar ( $p=1.0$ by KolmogorovSmirnov test).

ment of wild-type or BDNF -/- cerebellar slices with $200 \mathrm{ng} / \mathrm{ml}$ BDNF for $1 \mathrm{hr}$ was able to induce Trk receptor phosphorylation (data not shown).

\section{Synaptic vesicle distribution is altered in the absence of BDNF}

Under the experimental conditions used in this study, changes in the evoked response to pairs of stimuli are consistent with a presynaptic mechanism that regulates synaptic vesicle exocytosis. Recent studies have revealed the existence of distinct vesicle pools and have begun to shed light on their relationship to the dynamics of vesicle exocytosis and endocytosis (Sudhof, 1995; Betz and Angleson, 1998; Fernandez-Chacon and Sudhof, 1999; Jahn and Sudhof, 1999; Li and Schwarz, 1999; Doussau and Augustine, 2000; Sudhof, 2000). Because presynaptic function is impaired in BDNF $-/-$ mice, we hypothesized that this functional impairment may also be reflected in the synaptic ultrastructure.

Ultrastructural changes have previously been associated with changes in synaptic function. We performed a detailed analysis of the $\mathrm{PF} / \mathrm{PC}$ synapse in wild-type and $\mathrm{BDNF}-/-$ mice via electron microscopy. Electron micrographs of the molecular layer reveal the main ultrastructural components of the $\mathrm{PF} / \mathrm{PC}$ synapse in both genotypes (Fig. 7). These include a presynaptic swelling of the parallel fiber terminal, which contains numerous round, loosely packed synaptic vesicles. The postsynaptic dendritic spine from a Purkinje cell dendrite is also clearly visible in cross section. The asymmetric electron-dense band between the terminal and the dendritic spine is characteristic of excitatory synapses and is often used to demarcate the extent of the active zone. Although immunohistochemistry revealed the appropriate localization of important synaptic proteins, electron micrographs demonstrated conclusively that $\mathrm{PF} / \mathrm{PC}$ synapses display the basic structural features of synapses even in the absence of BDNF.

A quantitative analysis revealed a significant increase in the number of synaptic vesicles in the terminals of BDNF $-/-$ mice compared with those of BDNF $+/+$ mice (Table 1). Synaptic terminals were analyzed in longitudinal and cross-sectional orientations. The increase in vesicle number in BDNF -/- terminals was seen in both of these orientations. Investigations of the structure and dynamics of the vesicle pool have yielded evidence that it can be subdivided into different functional pools (Rosenmund and Stevens, 1996) that may exist in a steady-state relation-
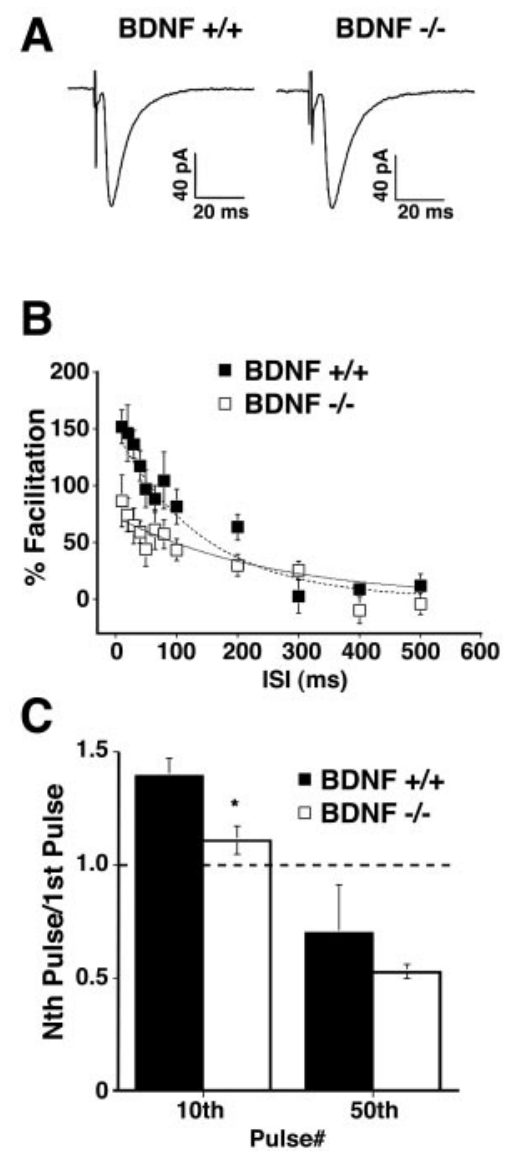

Figure 6. Specific impairment of short-term synaptic plasticity in BDNF $-1-$ mice. A, Evoked AMPA receptor-mediated EPSCs were elicited by stimulating parallel fibers and recording from an individual Purkinje cell in voltage clamp. The decay times of the evoked EPSCs are indistinguishable between WT and BDNF $-/-$ mice. Traces are the averages of 5-10 trials. $B$, The mean percentage facilitation is plotted as a function of interstimulus intervals for BDNF $-/-(\boldsymbol{\square} ; n=6)$ and wild-type littermates $(\square ; n=6)$. BDNF $-/-$ mice exhibit decreased paired-pulse facilitation at interstimulus intervals $<200 \mathrm{msec}(p<0.05)$. $C$, The response of Purkinje cells to repetitive $10 \mathrm{~Hz}$ stimulation is illustrated by plotting the ratio of the amplitude of the response to the 10th and 50th pulses to the amplitude of the response to the first pulse. Although 10th/1st ratio is significantly decreased in BDNF $-/-$ mice because of impaired PPF, there is no significant difference in the 50th/1st. This indicates that there is no difference in the response to prolonged $10 \mathrm{~Hz}$ stimulation in the absence of BDNF.

ship. Therefore, to determine whether the increase in the number of vesicles in BDNF $-/-$ mice was restricted to a specific region of the vesicle pool, we plotted the number of vesicles per $25 \mathrm{~nm}$ bin as a function of distance from the synaptic cleft (Fig. 8A,B). This revealed that within the first $100 \mathrm{~nm}$ of the synaptic cleft there is no difference in vesicle number. However, beyond $100 \mathrm{~nm}$ there is a significant increase in the number of vesicles in BDNF $-/-$ terminals ( $D \ll D_{0.01}$, by Kolmogorov-Smirnov). When we calculated the fraction of all the vesicles that was located within 50 $\mathrm{nm}$ of the active zone, commonly referred to as the docked vesicle pool, we found a significant decrease in the absence of BDNF (Table 1). These findings show that BDNF deficit leads to a selective increase in the vesicle pool that lies distal to the active zone.

Vesicle number may change as a function of synapse size. We found that PSD length was significantly increased in longitudinal 
BDNF +/+

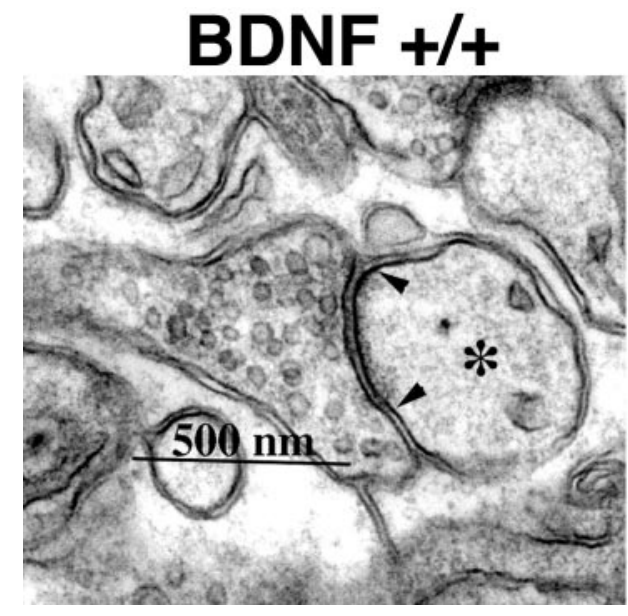

BDNF -/-

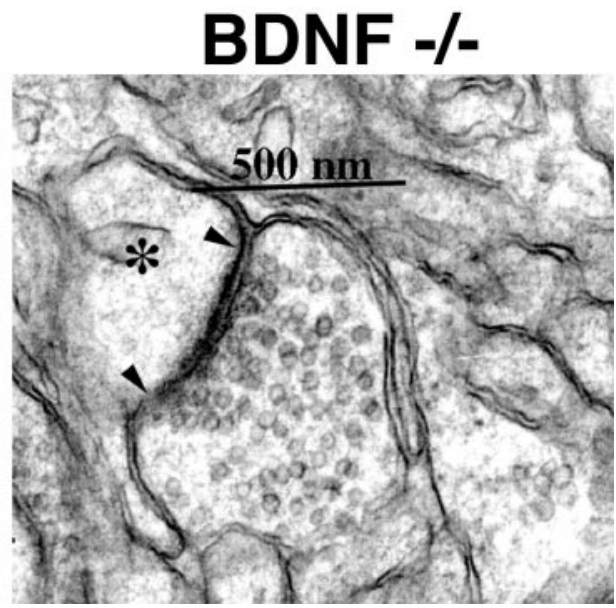

Figure 7. Electron micrographs of the $\mathrm{PF} / \mathrm{PC}$ synapse in $\mathrm{P} 15 \mathrm{WT}$ and $\mathrm{BDNF}-/-$ mice. Individual synapses exhibit a dendritic spine $(*)$, postsynaptic density demarcated by arrowheads, and presynaptic terminal filled with numerous round, loosely packed vesicles in both wild-type and BDNF $-/-$ animals.

Table 1. Ultrastructural analysis of PF/PC synapses in wild-type and BDNF - / - mice

\begin{tabular}{|c|c|c|c|c|c|}
\hline & $\begin{array}{l}\text { Vesicles/synapse } \\
( \pm \text { SEM })\end{array}$ & PSD (nm) & $\mathrm{DV} / \mu \mathrm{m} \mathrm{PSD}$ & $\begin{array}{l}\text { Ratio docked/ } \\
\text { total }\end{array}$ & Vesicles $/ \mu \mathrm{m}^{2}$ \\
\hline \multicolumn{6}{|c|}{ Longitudinal sections } \\
\hline$+/+$ & $49.8 \pm 2.9$ & $455.8 \pm 12.1$ & $20.9 \pm 0.7$ & $0.247 \pm 0.01$ & $346.1 \pm 8.4$ \\
\hline$-1-$ & $64.4 \pm 3.2^{*}$ & $517.1 \pm 13.4^{*}$ & $20.5 \pm 0.7$ & $0.193 \pm 0.01^{*}$ & $307.8 \pm 5.8^{*}$ \\
\hline \multicolumn{6}{|c|}{${ }^{*} p<0.01 ; \mathrm{BDNF}+/+(172$ synapses $) ; \mathrm{BDNF}-/-(177$ synapses $)$} \\
\hline \multicolumn{6}{|c|}{ Cross sections } \\
\hline$+/+$ & $18.9 \pm 1.8$ & $355.6 \pm 14.2$ & $17.4 \pm 0.9$ & $0.373 \pm 0.02$ & $347.8 \pm 11.9$ \\
\hline$-1-$ & $33.1 \pm 2.2^{*}$ & $357.0 \pm 9.4$ & $15.9 \pm 0.7$ & $0.214 \pm 0.01^{*}$ & $250.1 \pm 5.9^{*}$ \\
\hline
\end{tabular}

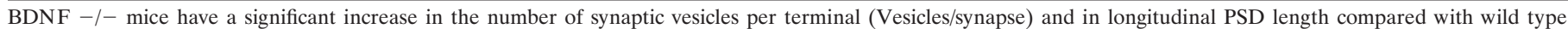

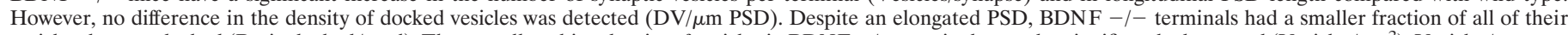

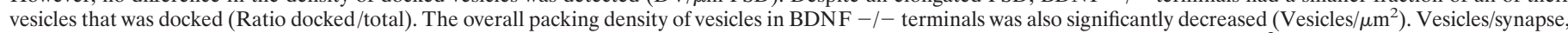

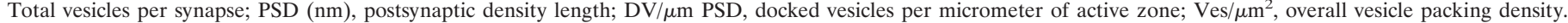
Numbers are mean $\pm \mathrm{SEM} ;{ }^{*} p<0.01$ by $t$ test.

sections of BDNF - / - terminals, suggesting an overall elongation of presynaptic terminals in the absence of BDNF. To correct for the effect of synapse size, the number of docked vesicles was normalized to the length of the active zone. Similarly, the total number of vesicles was normalized to the total area occupied by the vesicle pool (Table 1). We found that the density of docked vesicles was not significantly different between $\mathrm{BDNF}+/+$ and BDNF $-/-$ terminals (Table 1 ). In contrast, the overall packing density of vesicles was significantly decreased in the terminals of BDNF - / - mice compared with terminals in wild-type mice (Table 1). Therefore, parallel fibers terminals are not simply larger in BDNF $-/-$ mice, but exhibit an altered ultrastructure and abnormal distribution of vesicles that may reflect the change in synaptic function demonstrated here.

\section{DISCUSSION}

In the absence of BDNF, numerous PF/PC synapses form despite severe and persistent disturbances of Purkinje cell dendritic morphology. Although neurotransmission is remarkably well preserved, these synapses exhibit a specific defect in short-term synaptic plasticity. Although the amplitude of spontaneous mEPSCs, the waveforms of evoked EPSCs, and the response of the synapse to repetitive stimulation all appear normal, paired-pulse facilitation is significantly decreased in $\mathrm{BDNF}-/-$ mice. Changes in paired-pulse facilitation are often used as a measure of changes in presynaptic function. We found that this change is associated with a significant increase in synaptic vesicle number

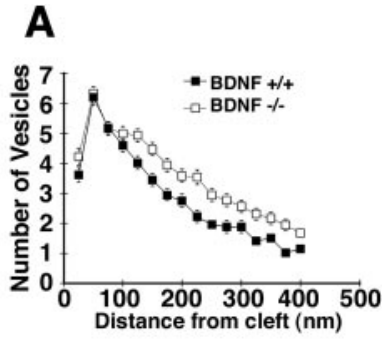

B

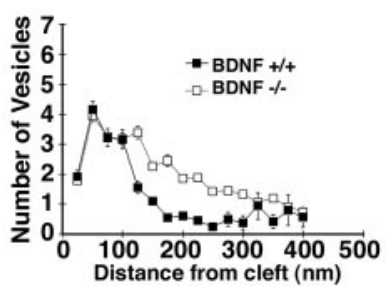

Figure 8. Increased vesicle number in BDNF -/- synapses is restricted to vesicles located farthest from the active zone. The number of vesicles within consecutive $25 \mathrm{~nm}$ bins was plotted as a function of distance from the synaptic cleft. Within the first $100 \mathrm{~nm}$ from the synaptic cleft there is no difference in the number of vesicles between the wild-type mice ( $\square$ ) and BDNF $-/-$ mice $(\square)$ in either longitudinal sections $(A)$ or cross sections $(B)$. However, beyond $100 \mathrm{~nm}$, BDNF $-/-$ mice exhibit a significant increase in the number of vesicles compared with WT mice. $* D \ll D_{0.01}$ by Kolmogorov-Smirnov. 
and a significant decrease in the overall synaptic vesicle packing density in BDNF - /- mice. The data presented here support a model in which BDNF in vivo acts on the $\mathrm{PF} / \mathrm{PC}$ synapse to modify short-term synaptic plasticity and regulate synaptic vesicle number and distribution.

\section{Correlating vesicle pools with synaptic function}

As is the case in the hippocampus in BDNF - /- mice (PozzoMiller et al., 1999) or TrkB -/- mice (Martinez et al., 1998), $\mathrm{BDNF}$ is not absolutely required for synaptogenesis between granule cells and Purkinje cells to take place. In fact, in the absence of BDNF, we detected only a slight decrease in the overall PF/PC synapse density. Accordingly, BDNF -/- Purkinje cell dendrites were studded with numerous spines as in wild-type cells, and most of theses spines were the sites of PF:PC synapses.

Although synaptogenesis proceeds, specific structural and functional abnormalities remain in BDNF $-/-$ mice. PF:PC synapses in BDNF - / - mice have more vesicles and longer PSDs than do wild-type synapses, whereas immature synapses are characterized by fewer vesicles and shorter PSDs. Thus the structural and physiologic differences seen in the PF/PC synapses of BDNF $-/-$ mice are not characteristics of developmentally delayed synapses but represent an aberrant phenotype. As demonstrated here for the cerebellum, decreased paired-pulse facilitation has been shown to be associated with structural changes in presynaptic terminals in the hippocampus of BDNF - / - (Pozzo-Miller et al., 1999) and TrkB -/- mice (Martinez et al., 1998). However, the nature of the ultrastructural changes is different in the two systems. Pozzo-Miller et al. (1999) observed a decrease in the number of docked vesicles in BDNF - /- mice. More recently, Tyler and Pozzo-Miller (2001) have demonstrated that BDNF applied to organotypic hippocampal slices increases docked vesicle number and neurotransmitter release. In contrast, in the cerebellum, we observed no change in docked vesicle density but rather an increase in vesicles distant from the active zone. How can we reconcile these apparent differences between the hippocampus and the cerebellum? In both systems the absence of BDNF results in a significant decrease in the proportion of synaptic vesicles that are docked relative to the total number of synaptic vesicles. Different vesicle pools are likely to exist in a dynamic steady state within the terminal (Li and Schwarz, 1999). Thus, one interpretation that reconciles the ultrastructural findings of the BDNF -/ hippocampus and cerebellum is that neurotrophins shift the balance between the different vesicle pools in favor of the docked pool. For example, BDNF could regulate the movement of synaptic vesicles within the terminal by modulating the interactions between motor proteins like myosin $\mathrm{V}$, cytoskeletal actin, and vesicle-associated proteins such as synapsin (Hilfiker et al., 1999; Doussau and Augustine, 2000).

This study of BDNF - / - cerebellar synapses provides a new example in which changes in presynaptic function correlate with alterations in vesicle number or vesicle distribution. In various systems, the degree of paired-pulse facilitation is inversely related to the number of docked vesicles (Dobrunz and Stevens, 1997; Murthy et al., 1997; Jiang and Abrams, 1998; Schikorski and Stevens, 1999). There are several examples in which mutations that alter the distribution of synaptic vesicles also lead to changes in presynaptic function. For example, mutations in synaptotagmin, the presynaptic calcium sensor, impair evoked neurotransmitter release (DiAntonio and Schwarz, 1994) and decrease the number of morphologically docked vesicles in Drosophila (Reist et al., 1998). Hippocampal synapses deficient in synapsin I, an abundant presynaptic phosphoprotein, exhibit increased pairedpulse facilitation (Rosahl et al., 1993) and a significant decrease in the number of vesicles distal to the active zone (Takei et al., 1995). The unconventional myosin, myosin Va, is a motor protein that may contribute to actin-based vesicle movement in synaptic terminals (Prekeris and Terrian, 1997). In mice, mutations in myosin Va lead to progressive ataxia, loss of balance, seizures, and death (Evans et al., 1997), and in humans they lead to a rare immunodeficiency and pigmentation disorder, Griscelli syndrome (Kumar et al., 2001). Cerebellar granule cells in myosin Va mutant animals have enlarged synaptic terminals with increased numbers of vesicles suggesting the abnormal accumulation of presynaptic components (Bridgman, 1999). Acute changes in synaptic proteins can likewise alter both vesicle distribution and presynaptic function. The injection of anti-synapsin antibodies into lamprey axons depletes the distal pool of vesicles and results in a pronounced decrease in EPSP amplitude in response to high-frequency but not low-frequency stimulation (Pieribone et al., 1995). These studies are essential in helping to elucidate the relationship between synaptic vesicle distribution and synaptic function at various types of synapses. Here we have shown that facilitation is impaired in enlarged terminals where vesicles accumulate in the absence of BDNF. The increase in parallel fiber terminal size and decrease in overall vesicle density in the absence of BDNF are similar to the changes observed in the terminals of hippocampal afferents in TrkB $-/-$ mice (Martinez et al., 1998) as well as in parallel fiber terminals of myosin Va mutant mice (Bridgman, 1999) and suggest a common underlying abnormality.

\section{Chronic and acute effects of BDNF}

The changes in BDNF $-/-$ mice reported here could reflect either the long-term effects of BDNF deficit on synapse development or the acute effects of BDNF deficit on synaptic function. Neurotrophins are powerful differentiation factors and may guide the recruitment and assembly of the molecular components required for synaptic function and/or plasticity. Thus alterations in short-term plasticity and synaptic ultrastructure may represent abnormal development. This idea is consistent with the finding that exogenous BDNF fails to reverse the defect in PPF. If the changes in BDNF $-/-$ mice are caused by long-term BDNF deprivation, then BDNF rescue may require days.

Alternatively, the effects of BDNF on synaptic plasticity could be very acute and depend on the timing of endogenous BDNF release at active synapses. Bath application of BDNF may fail to reproduce the in vivo time course and hence fail to reverse the defect in PPF. Recent studies have demonstrated that BDNF is located within vesicles at the presynaptic terminal (Haubensak et al., 1998) and can be rapidly released in response to activity (Canossa et al., 1997; Marini et al., 1998). BDNF can also potentiate neurotransmitter release from cerebellar granule neurons (Numakawa et al., 1999; Yamagishi et al., 2000) and can cause a rapid depolarization of Purkinje cells (Kafitz et al., 1999). These rapid and local effects of BDNF may not be mimicked by prolonged bath application of neurotrophin.

Finally, the inability of exogenous BDNF to alter facilitation could reflect a postsynaptic role of BDNF. The experimental conditions used here detect changes in presynaptic function exclusively (see Materials and Methods). Thus, if endogenous BDNF acts on postsynaptic TrkB receptors and induces the release of a trans-synaptic retrograde signal such as a cannabinoid 
(Kreitzer and Regehr, 2001; Maejima et al., 2001) or adenosine to alter paired-pulse facilitation, we would not detect any change in PPF after application of exogenous BDNF.

Taken together, the data presented here suggest that BDNF can regulate the degree of short-term synaptic plasticity that can be elicited at a synapse. Given that neurotrophin expression and release are activity dependent, neurotrophins may be important mediators of hebbian plasticity by providing neuronal circuits with a mechanism by which plasticity is favored at more active synapses. Such second-order plasticity, or metaplasticity, constitutes a powerful additional dimension in which neurons can adjust the strength of their connections to achieve their information-processing goals.

\section{REFERENCES}

Atluri PP, Regehr WG (1998) Delayed release of neurotransmitter from cerebellar granule cells. J Neurosci 18:8214-8227.

Berninger B, Schinder AF, Poo MM (1999) Synaptic reliability correlates with reduced susceptibility to synaptic potentiation by brainderived neurotrophic factor. Learn Mem 6:232-242.

Betz WJ, Angleson JK (1998) The synaptic vesicle cycle. Annu Rev Physiol 60:347-363.

Bolshakov VY, Siegelbaum SA (1995) Regulation of hippocampal transmitter release during development and long-term potentiation. Science 269:1730-1734.

Bridgman PC (1999) Myosin Va movements in normal and dilute-lethal axons provide support for a dual filament motor complex. J Cell Biol 146:1045-1060.

Canossa M, Griesbeck O, Berninger B, Campana G, Kolbeck R, Thoenen H (1997) Neurotrophin release by neurotrophins: implications for activity-dependent neuronal plasticity. Proc Natl Acad Sci USA 94:13279-13286.

Chen C, Regehr WG (1997) The mechanism of cAMP-mediated enhancement at a cerebellar synapse. J Neurosci 17:8687-8694.

DiAntonio A, Schwarz TL (1994) The effect on synaptic physiology of synaptotagmin mutations in Drosophila. Neuron 12:909-920.

Dobrunz LE, Stevens CF (1997) Heterogeneity of release probability, facilitation, and depletion at central synapses. Neuron 18:995-1008.

Doussau F, Augustine GJ (2000) The actin cytoskeleton and neurotransmitter release: an overview. Biochimie 82:353-363.

Ernfors P, Lee KF, Jaenisch R (1994) Mice lacking brain-derived neurotrophic factor develop with sensory deficits. Nature 368:147-150.

Evans LL, Hammer J, Bridgman PC (1997) Subcellular localization of myosin $\mathrm{V}$ in nerve growth cones and outgrowth from dilute-lethal neurons. J Cell Sci 110:439-449.

Fernandez-Chacon R, Sudhof TC (1999) Genetics of synaptic vesicle function: toward the complete functional anatomy of an organelle. Annu Rev Physiol 61:753-776.

Figurov A, Pozzo-Miller LD, Olafsson P, Wang T, Lu B (1996) Regulation of synaptic responses to high-frequency stimulation and LTP by neurotrophins in the hippocampus. Nature 381:706-709.

Gottschalk W, Pozzo-Miller LD, Figurov A, Lu B (1998) Presynaptic modulation of synaptic transmission and plasticity by brain-derived neurotrophic factor in the developing hippocampus. J Neurosci 18:6830-6839.

Haubensak W, Narz F, Heumann R, Lessmann V (1998) BDNF-GFP containing secretory granules are localized in the vicinity of synaptic junctions of cultured cortical neurons. J Cell Sci 111:1483-1493.

Hilfiker S, Pieribone VA, Czernik AJ, Kao HT, Augustine GJ, Greengard P (1999) Synapsins as regulators of neurotransmitter release. Philos Trans R Soc Lond B Biol Sci 354:269-279.

Hofer M, Pagliusi SR, Hohn A, Leibrock J, Barde YA (1990) Regional distribution of brain-derived neurotrophic factor mRNA in the adult mouse brain. EMBO J 9:2459-2464.

Jahn R, Sudhof TC (1999) Membrane fusion and exocytosis. Annu Rev Biochem 68:863-911.

Jiang XY, Abrams TW (1998) Use-dependent decline of paired-pulse facilitation at Aplysia sensory neuron synapses suggests a distinct vesicle pool or release mechanism. J Neurosci 18:10310-10319.

Kafitz KW, Rose CR, Thoenen H, Konnerth A (1999) Neurotrophinevoked rapid excitation through TrkB receptors. Nature 401:918-921.

Kang H, Schuman EM (1995a) Long-lasting neurotrophin-induced enhancement of synaptic transmission in the adult hippocampus. Science 267:1658-1662.

Kang HJ, Schuman EM (1995b) Neurotrophin-induced modulation of synaptic transmission in the adult hippocampus. J Physiol (Paris) 89:11-22.

Katz B, Miledi R (1968) The role of calcium in neuromuscular facilitation. J Physiol (Lond) 195:481-492.
Klein R, Martin-Zanca D, Barbacid M, Parada LF (1990) Expression of the tyrosine kinase receptor gene trkB is confined to the murine embryonic and adult nervous system. Development 109:845-850.

Korte M, Carroll P, Wolf E, Brem G, Thoenen H, Bonhoeffer T (1995) Hippocampal long-term potentiation is impaired in mice lacking brainderived neurotrophic factor. Proc Natl Acad Sci USA 92:8856-8860.

Korte M, Griesbeck O, Gravel C, Carroll P, Staiger V, Thoenen H, Bonhoeffer T (1996a) Virus-mediated gene transfer into hippocampal CA1 region restores long-term potentiation in brain-derived neurotrophic factor mutant mice. Proc Natl Acad Sci USA 93:12547-12552.

Korte M, Staiger V, Griesbeck O, Thoenen H, Bonhoeffer T (1996b) The involvement of brain-derived neurotrophic factor in hippocampa long-term potentiation revealed by gene targeting experiments. J Physiol (Paris) 90:157-164.

Kreitzer AC, Regehr WG (2000) Modulation of transmission during trains at a cerebellar synapse. J Neurosci 20:1348-1357.

Kreitzer AC, Regehr WG (2001) Retrograde inhibition of presynaptic calcium influx by endogenous cannabinoids at excitatory synapses onto Purkinje cells. Neuron 29:717-727.

Kumar M, Sackey K, Schmalstieg F, Trizna Z, Elghetany MT, Alter BP (2001) Griscelli syndrome: rare neonatal syndrome of recurrent hemophagocytosis. Am J Pediatr Hematol Oncol 23:464-468.

Landsend AS, Amiry-Moghaddam M, Matsubara A, Bergersen L, Usami S, Wenthold RJ, Ottersen OP (1997) Differential localization of $\delta$ glutamate receptors in the rat cerebellum: coexpression with AMPA receptors in parallel fiber-spine synapses and absence from climbing fiber-spine synapses. J Neurosci 17:834-842.

Lessmann V, Gottmann K, Heumann R (1994) BDNF and NT-4/5 enhance glutamatergic synaptic transmission in cultured hippocampal neurones. NeuroReport 6:21-25.

Levine ES, Dreyfus CF, Black IB, Plummer MR (1995) Brain-derived neurotrophic factor rapidly enhances synaptic transmission in hippocampal neurons via postsynaptic tyrosine kinase receptors. Proc Natl Acad Sci USA 92:8074-8077.

Li J, Schwarz TL (1999) Genetic evidence for an equilibrium between docked and undocked vesicles. Philos Trans R Soc Lond B Biol Sci 354:299-306.

Li YX, Xu Y, Ju D, Lester HA, Davidson N, Schuman EM (1998) Expression of a dominant negative TrkB receptor, T1, reveals a requirement for presynaptic signaling in BDNF-induced synaptic potentiation in cultured hippocampal neurons. Proc Natl Acad Sci USA 95:10884-10889.

Lu B, Chow A (1999) Neurotrophins and hippocampal synaptic transmission and plasticity. J Neurosci Res 58:76-87.

Lu B, Figurov A (1997) Role of neurotrophins in synapse development and plasticity. Rev Neurosci 8:1-12.

Maejima T, Hashimoto K, Yoshida T, Aiba A, Kano M (2001) Presynaptic inhibition caused by retrograde signal from metabotropic glutamate to cannabinoid receptors. Neuron 31:463-475.

Marini AM, Rabin SJ, Lipsky RH, Mocchetti I (1998) Activitydependent release of brain-derived neurotrophic factor underlies the neuroprotective effect of $N$-methyl-D-aspartate. J Biol Chem 273:29394-29399.

Martinez A, Alcantara S, Borrell V, Del Rio JA, Blasi J, Otal R, Campos N, Boronat A, Barbacid M, Silos-Santiago I, Soriano E (1998) TrkB and TrkC signaling are required for maturation and synaptogenesis of hippocampal connections. J Neurosci 18:7336-7350.

McAllister AK, Katz LC, Lo DC (1999) Neurotrophins and synaptic plasticity. Annu Rev Neurosci 22:295-318.

Morrison ME, Mason CA (1998) Granule neuron regulation of Purkinje cell development: striking a balance between neurotrophin and glutamate signaling. J Neurosci 18:3563-3573.

Murthy VN, Sejnowski TJ, Stevens CF (1997) Heterogeneous release properties of visualized individual hippocampal synapses. Neuron 18:599-612.

Numakawa T, Takei N, Yamagishi S, Sakai N, Hatanaka H (1999) Neurotrophin-elicited short-term glutamate release from cultured cerebellar granule neurons. Brain Res 842:431-438.

Patterson SL, Abel T, Deuel TA, Martin KC, Rose JC, Kandel ER (1996) Recombinant BDNF rescues deficits in basal synaptic transmission and hippocampal LTP in BDNF knockout mice. Neuron 16:1137-1145.

Pieribone VA, Shupliakov O, Brodin L, Hilfiker-Rothenfluh S, Czernik AJ, Greengard P (1995) Distinct pools of synaptic vesicles in neurotransmitter release. Nature 375:493-497.

Pozzo-Miller LD, Gottschalk W, Zhang L, McDermott K, Du J, Gopalakrishnan R, Oho C, Sheng ZH, Lu B (1999) Impairments in high-frequency transmission, synaptic vesicle docking, and synaptic protein distribution in the hippocampus of BDNF knock-out mice. J Neurosci 19:4972-4983

Prekeris R, Terrian DM (1997) Brain myosin V is a synaptic vesicleassociated motor protein: evidence for a $\mathrm{Ca} 2+$-dependent interaction with the synaptobrevin-synaptophysin complex. J Cell Biol 137:1589-1601.

Reist NE, Buchanan J, Li J, DiAntonio A, Buxton EM, Schwarz TL 
(1998) Morphologically docked synaptic vesicles are reduced in synaptotagmin mutants of Drosophila. J Neurosci 18:7662-7673.

Rosahl TW, Geppert M, Spillane D, Herz J, Hammer RE, Malenka RC, Sudhof TC (1993) Short-term synaptic plasticity is altered in mice lacking synapsin I. Cell 75:661-670.

Rosenmund C, Stevens CF (1996) Definition of the readily releasable pool of vesicles at hippocampal synapses. Neuron 16:1197-1207.

Sabatini BL, Regehr WG (1997) Control of neurotransmitter release by presynaptic waveform at the granule cell to Purkinje cell synapse. J Neurosci 17:3425-3435.

Schikorski T, Stevens CF (1999) Quantitative fine-structural analysis of olfactory cortical synapses. Proc Natl Acad Sci USA 96:4107-4112.

Schulz PE, Cook EP, Johnston D (1994) Changes in paired-pulse facilitation suggest presynaptic involvement in long-term potentiation. J Neurosci 14:5325-5337.

Schuman EM (1999) Neurotrophin regulation of synaptic transmission. Curr Opin Neurobiol 9:105-109.

Schwartz PM, Borghesani PR, Levy RL, Pomeroy SL, Segal RA (1997) Abnormal cerebellar development and foliation in BDNF-/- mice reveals a role for neurotrophins in CNS patterning. Neuron 19:269-281.

Segal RA, Pomeroy SL, Stiles CD (1995) Axonal growth and fasciculation linked to differential expression of BDNF and NT3 receptors in developing cerebellar granule cells. J Neurosci 14:4970-4981.
Shimada A, Mason CA, Morrison ME (1998) TrkB signaling modulates spine density and morphology independent of dendrite structure in cultured neonatal Purkinje cells. J Neurosci 18:8559-8570.

Stoop R, Poo MM (1996) Synaptic modulation by neurotrophic factors: differential and synergistic effects of brain-derived neurotrophic factor and ciliary neurotrophic factor. J Neurosci 16:3256-3264.

Sudhof TC (1995) The synaptic vesicle cycle: a cascade of proteinprotein interactions. Nature 375:645-653.

Sudhof TC (2000) The synaptic vesicle cycle revisited. Neuron 28:317-320.

Takei Y, Harada A, Takeda S, Kobayashi K, Terada S, Noda T, Takahashi T, Hirokawa N (1995) Synapsin I deficiency results in the structural change in the presynaptic terminals in the murine nervous system. J Cell Biol 131:1789-1800.

Tyler WJ, Pozzo-Miller LD (2001) BDNF enhances quantal neurotransmitter release and increases the number of docked vesicles at the active zones of hippocampal excitatory synapses. J Neurosci 21:4249-4258.

Yamagishi S, Fujikawa N, Kohara K, Tominaga-Yoshino K, Ogura A (2000) Increased exocytotic capability of rat cerebellar granule neurons cultured under depolarizing conditions. Neuroscience 95:473-479.

Zucker RS (1989) Short-term synaptic plasticity. Annu Rev Neurosci 12:13-31. 